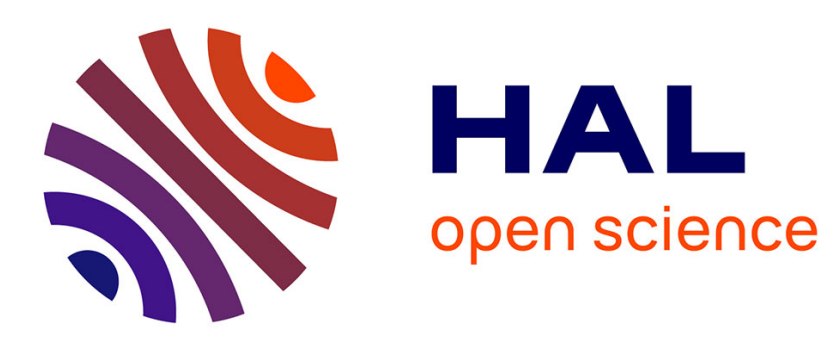

\title{
The origins of old age psychiatry in Britain in the 1940s
}

Claire Hilton

\section{To cite this version:}

Claire Hilton. The origins of old age psychiatry in Britain in the 1940s. History of Psychiatry, 2005, 16 (3), pp.267-289. 10.1177/0957154X05050075 . hal-00570819

\section{HAL Id: hal-00570819 https://hal.science/hal-00570819}

Submitted on 1 Mar 2011

HAL is a multi-disciplinary open access archive for the deposit and dissemination of scientific research documents, whether they are published or not. The documents may come from teaching and research institutions in France or abroad, or from public or private research centers.
L'archive ouverte pluridisciplinaire HAL, est destinée au dépôt et à la diffusion de documents scientifiques de niveau recherche, publiés ou non, émanant des établissements d'enseignement et de recherche français ou étrangers, des laboratoires publics ou privés. 


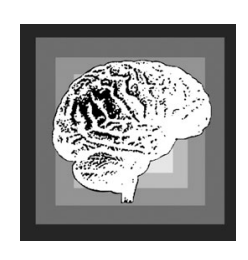

\title{
The origins of old age psychiatry in Britain in the 1940s
}

\author{
CLAIRE HILTON* \\ Northwick Park Hospital, UK
}

In the 1940s, some of the most influential psychiatrists of their day such as David K. Henderson and Aubrey Lewis were taking an active interest in the well-being of older people. Spurred on by the fears of a rising population of older people, overcrowding in mental hospitals, social changes and an awareness of the lack of knowledge of older people's mental illnesses, they and others began to explore further the mental health needs of older people. There was a marked change from a predominant interest in neuropathology in older mental hospital patients to emphasis on the need to provide clinical care and treatment for people in the community. The establishment of the new specialty of geriatric medicine and inception of the National Health Service gave further impetus to service development.

Keywords: Aubrey Lewis; dementia; geriatrics; history; mental hospitals; old age psychiatry; UK

\section{Introduction}

During World War II, beds in mental hospitals were requisitioned for military purposes, traditional home carers - women - were employed in war work, and the population and life expectancy of older people was rising (Table 1). At the same time as Marjory Warren (1943) was drawing the nation's attention to the plight of older physically ill people, the mental well-being of older people was also becoming a pressing issue.

Old age psychiatry combines psychiatric history and examination with neuropsychiatry, psychological assessment, medical and social factors and

* Address for correspondence: Northwick Park Hospital, Watford Road, Harrow, HA1 3UJ, UK. Email: claire.hilton@nhs.net 
TABLE 1. Great Britain: numbers aged 60 years or over (BMA, 1947)

\begin{tabular}{cccc}
\hline Year & Men & Women & Total \\
\hline 1901 & $1,071,519$ & $1,336,907$ & $2,408,426$ \\
1939 & $2,511,200$ & $3,197,400$ & $5,708,600$ \\
1944 & $2,737,000$ & $3,590,000$ & $6,327,000$ \\
1946 & $2,828,000$ & $3,759,000$ & $6,587,000$ \\
\hline
\end{tabular}

TABLE 2. Great Britain: expectation of life (BMA, 1947)

\begin{tabular}{lcc}
\hline Year(s) & Men (years) & Women (years) \\
\hline $1891-1900$ & 44.1 & 47.8 \\
$1901-1910$ & 48.5 & 52.4 \\
1942 & 61.7 & 67.4 \\
\hline
\end{tabular}

other parameters of ageing with the objective of preventing and treating psychiatric illness in older people. It has been a specialty recognized by the Department of Health only since 1989. A conference in March 2003 of the Faculty for the Psychiatry of Old Age of the Royal College of Psychiatrists claimed to celebrate 30 years of old age psychiatry, but this dated only from the foundation of the Group for the Psychiatry of Old Age at the Royal College of Psychiatrists. This Group, and latterly its development into a Faculty, has had a profound effect on influencing the provision of services and treatment for older people with mental illness. However, the work of earlier pioneers in the field has to a large extent been forgotten.

This paper explores developments between 1940 and 1949 in the provision of care and treatment for older people with psychiatric illness, drawing mainly on scientific research and review papers published during this period. Although some publications may reflect slightly earlier research, dates of publication rather than dates of research are used for source material because information readily available is likely to reflect on the dissemination of knowledge during the period and therefore the potential for influencing clinical practice. 


\section{The 1930s and early 1940s}

The dearth of literature on a philosophy of care and the provision of treatment for older people with mental illness in the 1930s and early 1940s is readily apparent from both the general medical and psychiatric literature in Britain. A survey of a leading medical journal The Lancet and an influential psychiatric journal the Fournal of Mental Science from 1935 onwards revealed little of any clinical significance relating to older people's mental health. From the physical illness perspective, however, the popular belief of the futility for operative treatment for people of 'advanced age' was being challenged (Anon., 1937a; Anon., 1939). On the social side, there was a plea for more humane accommodation for older people, such as the provision of curtains between beds (Anon., 1937b). Discussions on the distinction between 'pathological' changes of ageing against 'senile' changes were inconclusive, but generally tended to err on the side of the senile domain, i.e., that deterioration was inevitable rather than as a result of illness and therefore was not amenable to treatment (Anon., 1935a, Anon., 1938). A paper on 'Some common mental disorders' mentioned confusion, but not in the context of old age (Anon., 1935b). There was an occasional review of a book with implications for older people's care, including one book with the ominous title Care of the Aged, the Dying and the Dead (Anon., 1935c).

In the field of mental illness, various issues of concern were reflected in the Fournal of Mental Science, published by the Royal Medico-Psychological Association (RMPA), the forerunner of the Royal College of Psychiatrists. In the late 1930s there appeared to be no mention of older people whatsoever. In the early 1940s, prominent reports featured current clinical issues such as children's mental health, the use of induced seizures for treating psychiatric disorders, new techniques of intelligence testing and wartime psychological problems. There were many papers related to organic conditions which occur more commonly with increasing age, but no work on the clinical impact of these conditions on older people. In 1940 the only papers on mental illness in older people were on ascorbic acid levels in 'senile psychoses' (Berkenau, 1940; Remp, Rosen, Ziegler and Cameron, 1940). The methodology included lumbar punctures to measure cerebro-spinal fluid levels of ascorbic acid and showed little respect for the well-being of the older people under investigation, let alone an active interest in their care and treatment.

The 1942 volume of the Fournal of Mental Science had two papers of potential relevance to care of older people by M. B. Brody at Runwell Hospital in Essex. Brody $(1942 a, 1942 b)$ used a battery of neuropsychiatric assessment scales to assess in-patients with and without dementia. However, his papers merely reflected the interest of the period on the neuropathology and neuropsychology of the various conditions, and not on how to improve the well-being and health of older people. A similar pattern of interest also 
appeared in literature of the same period in the USA. In 'Old age and ageing: the present status of scientific knowledge' (Lawton, 1940), most of the contributors focused on the process and pathology of ageing, largely neglecting the management of illnesses affecting older people.

In 1938 Dr Aubrey Lewis visited almost all European centres of excellence in psychiatry 'to learn what was being done in neuropsychiatry and related fields'. He mentioned child psychiatry, and 'the need for specialisation within the psychiatric field', but not clinical care, treatment or facilities for older people (Lewis, 2003). Felix Post, working as an old age psychiatrist by 1949, noted that despite the excellence of training in neuropsychiatry in pre-war Germany, the interaction of social factors so important in the care the mental health of older people was not recognized (Post, 1991)

In 1944 in the Fournal of Mental Science, a paper on 'Mental health services - present and future' failed to mention any issues specifically related to older people (Petrie, 1944). In the same volume, a review by Mayer-Gross (1944) on 'Arteriosclerotic, senile and presenile psychoses' focused on dementias over a range of ages. Mayer-Gross criticized the lack of emphasis in recently published texts, such as Cowdry's Problems of Ageing (1942), for showing little interest in the clinical implications of dementia and social and medical problems associated with it. Despite this criticism, his paper also took a traditional standpoint of investigating just the neuropathology of diseases likely to affect older people, rather than their clinical implications. Literature from the USA had a similar focus (Schilder, 1940). One must not, however, underestimate the huge importance of pathological studies to our understanding of mental illness. Comments by Mayer-Gross (1945) do suggest the start of some attention to how to bridge the gap between neuropathological findings and the care of older people.

By this time, Warren's seminal paper 'Care of the chronic sick' (1943) had been published in the British Medical fournal. Although she clearly included the need for appropriate care for older people with dementia, for the next few years the development of old age psychiatry ran parallel to her work, rather than joining with it.

\section{Influences from Edinburgh on the beginning of old age psychiatry}

One of the leading psychiatrists of his day was Professor David K. Henderson, working in Edinburgh. Erwin Stengel (1943) stated: 'In this country Henderson was the first to draw attention to the considerable importance of Alzheimer's disease in clinical psychiatry'. Two notable papers of the mid-1940s were also written with Henderson's encouragement, one on the diagnosis of dementia by Erwin Stengel (1943) and another on clinical features of mental illness in older people by Felix Post (1944). Both Post and Stengel acknowledged Henderson's influence.

At the time of their research, both men were working in Edinburgh with 
Henderson, having been refugees from Nazi Europe. Stengel was an eminent Jewish psychiatrist from the department of psychiatry and neurology at the University in Vienna who fled to Britain shortly before World War II (Anon., 1973). Post, his junior by some years, related in an interview how they got to know each other:

Fortunately, Erwin Stengel, as a research assistant on a grant, found employment just before or after I got there, having moved from Crichton Royal, Dumfries. Stengel wanted to spend time with the younger people. He was accessible; he and his wife were hospitable and helpful. He would see patients with me, whenever I had a problem, and would spend a lot of time. He taught me psychiatry. (Post, 1988)

Stengel (1943) appears to have been one of the first to query the assumptions prevalent at the time that 'senile dementia' was different from Alzheimer's disease, and that dementia in old age was a physiological part of ageing rather than a disease process. He stated that 'the differential diagnosis between Alzheimer's Disease developing late and senile dementia may be difficult or even impossible'. His paper, with a personal and social history of each patient he described, focused on how the illness affected the individual and their family, rather than specifically the neuropathology evident in the brain. Thus, Stengel gave a far more holistic view of the sufferer's needs than was generally apparent from other contemporary British sources.

The relationship between senile dementia, Alzheimer's disease and normal ageing was further explored by Newton (1948). He investigated the brains of 150 autopsies at a mental hospital to look for pathological changes related to these three conditions. All three had some similar pathological changes. However, he observed no pathological differences between pre-senile Alzheimer's and senile dementias. That older people were suffering from a specific illness, rather than just an inevitable consequence of ageing, was a major step in the philosophy of treatment and care of older people. It had taken 40 years from the time of Alzheimer's description of the condition in a middle-aged woman until it was recognized that the same pathological process was occurring in older people. It took considerably more research until this became widely appreciated.

By 1944 Post had already obtained his membership of the Royal College of Physicians of London (MRCP) and Diploma in Psychological Medicine (DPM), the only qualification in psychiatry available at that time. Many years later, he recalled how his study on older people had come about:

When I was in Edinburgh, on the wards in Craig House, at the end of a round, Henderson said 'See all these poor old people here, Post. Why don't you write them up.' So I did write them up, in the usual way. How many patients there were, how many years they had been there, and what their diagnoses were. (Post, 1988)

Post's 1944 paper reflected the level of knowledge at the time coupled with 
his own observations. Unusually for the time, he confined his observations to people over the age of 60 years. This contrasted with other studies where older people merely represented the tail end of a larger study, a situation which was still common even in the 1960s (Affleck, 1948; Mayer-Gross, 1945; Stengel, 1965). Post emphasized both the increasing proportion of older people in the population in Scotland (aged over 60 years: 7.6\% in 1901 and $13.0 \%$ in 1941), and the increasing number of older people admitted to the Royal Edinburgh Hospital for Nervous and Mental Disorders. He made a clear distinction between 'involutional melancholia' (depression) and dementia in older people. Post (1962) knew that this had been evident for many years in the German psychiatric literature. However, it was not really recognized within British psychiatry, where symptoms of depression were assumed to be part of a dementia in old age rather than a specific entity in their own right. Post therefore anticipated by 8 years the influential findings of Roth and Morrissey (1952) on the differential diagnosis of these conditions in older people.

Within the same paper he went on to acknowledge the role of acute physical illness in dementia inducing delirium and disturbed behaviour, and therefore leading to admission to mental hospital. He wrote: 'in avoiding breakdowns necessitating admission to a mental hospital, early recognition and treatment of physical illness and provision of adequate nutrition as well as sleep are the main prophylactic measures.' He went on to explore the role of occupational therapy in rehabilitation, and to comment on new social developments: 'interesting suggestions have been made recently for the social prophylaxis of senile mental illness; they range from the creation of social clubs for the aged to the building of special blocks of flats where old people can lead a community life'. Some of Post's assumptions may be incorrect, such as that social factors can prevent dementia. But he was willing to explore the social influences in a holistic, eclectic, multidisciplinary way, on psychiatric illness in older people and how their lives could be improved. In 1944 this was a new approach to mental illness in older people. Interestingly he did not refer to the recently published paper by Warren (1943), but just to the psychiatric literature. She was working with chronically sick elderly longstay patients at the West Middlesex County Hospital, focusing on rehabilitation and improving the environment for those in hospital. In contrast, Post's approach was one of establishing correct diagnosis and instituting prophylactic measures to prevent illness and admissions to hospital. Although they shared common ground, such as concern over the increasing population of older people and the interface between mental and physical illness, their work was developing entirely independently.

\section{The influence of Professor Sir Aubrey Lewis}

Widely recognized as one of the leading psychiatrists of his generation, 
Aubrey Lewis took an interest in the mental health of older people. He was appointed Professor of Psychiatry at the Maudsley Hospital in 1946, having been clinical director there during World War II. In 1943 he published a paper on 'Social causes for admission to a mental hospital for the aged' (Lewis and Goldschmidt, 1943). In the same year as Post's paper, there was a more general leading article in The Lancet, attributed to Aubrey Lewis (Lewis, 1944; Shepherd, 1986). This looked more generally at issues around ageing, but with the same emphasis as in his other writing on the links between medical and social problems in older people. He suggested that the principles of the new Disabled Persons Employment Act 1944 should be applied to older people, helping them to continue to work into their later years even if jobs had to be adjusted to their needs. He also criticized the lack of research into ageing. Lewis published another paper on older people in 1946.

The impetus for Lewis's work appears to have been the increasing population of older people and their occupation of mental hospital beds. However, he also had a long-term interest in the social aspects of psychiatry, leading to him later setting up the Medical Research Council Social Psychiatry Unit. Data relating to higher proportions of older people being admitted to mental hospitals, and the increasing numbers of people of 'pensionable age' in the population were quoted in Lewis and Goldschmidt's work (1943; see also Table 1). Their paper focused on the social factors which had led to the admission of older people to Tooting Bec Hospital.

This hospital which was only a few miles from the Maudsley Hospital accommodated over 2000 elderly mentally ill patients. It would have been a prime focus for any local psychiatrist with a progressive outlook and interest in older people at that time. Lewis and Goldschmidt (1943) investigated a sample of 25 men and 25 women (age range 65-91 years) admitted to Tooting Bec Hospital. All admissions had an organic diagnosis, and none were diagnosed with depression or functional psychotic illnesses; Tooting Bec Hospital was specifically for the care of older people with dementia (Post, 1951). The study investigated the social factors which appeared to contribute to admission, which included social integration, previous occupation, financial security, diet, physical health, effect of war conditions, previous mental health and 'ultimate social failure'. In essence, if social factors had an influence, there was something that could be done to intervene and prevent admission or enable discharge. Lewis and Goldschmidt concluded that:

Lapses of conduct which make admission to mental hospital imperative are usually severe, though the illness of which they are the evidence may not be: social criteria of the severity of morbid behaviour are sometimes very different from medical ones. It is a mistake to infer that because the patients admitted to Tooting Bec are senile, their illness must be a progressive dementia and the outlook for improvement dark. It is a social quite as often as a medical breakdown that compels their admission, and 
a social improvement sometimes makes it possible for them to leave hospital ... The investigation indicated the need for non-residential advisory centres for the ageing and aged. These should be staffed by doctors, psychologists, and social workers familiar with the problems of this period of life, very much on the lines of a child guidance clinic. The success of such centres will be bound up with the wider measures the community takes to cater for the special needs of the elderly.

By the 1940s there was already the potential for change in the care of older mentally ill people. For example, the 1929 Local Government Act marked the end of the Poor Law, the 1930 Mental Treatment Act introduced voluntary in-patient admissions and out-patient clinics, and the 1944 White Paper on health emphasized the need for closer links between mental hospitals and general hospitals (Rogers and Pilgrim, 1996). Even before the 1930 Act, Tooting Bec Hospital was admitting mentally ill older people informally without detaining them (McInness, 1990). Child guidance clinics as referred to by Lewis and Goldschmidt (1943) were already well established, the first having been established in London by Emmanuel Miller in 1927 (Wardle, 1989). They functioned as multi-disciplinary teams. Over 50 were opened before World War II (Petrie, 1944). Lewis and Goldschmidt proposed them as a model for modern care of older mentally ill people in Britain, and a similar model had already been piloted at the Old Age Centre in San Francisco in the USA. It was set up by a psychologist, Dr Lillian J. Martin, when she herself was 70 years of age, having earlier developed child guidance clinics (Lawton, 1944; Peters, 1944). However, the clinics appear to have concentrated on helping people adapt to the ageing process rather than as interventions for mental illness. Despite this, they were observed to have had some success in improving older peoples' quality of life, for example:

Dr Martin assures her clients, after watching them at their own gait, that
most of them can move much faster. She sets them to finding a new
tempo, which they are expected to maintain. As this is one of the most
criticized features of her technique, I secretly wondered if her
rehabilitated clients actually did die off earlier, or meet with accidents, or
in any way suffered from following her advice. I saw no indications of
such consequences, and I actually observed a good many of her
restorations in their clubs. There was no doubt that they seemed more
interested in what they were doing than is the case with many old people.
(Peters, 1944)

Lewis, like Post, did not refer to the pioneering work of Warren $(1943,1946)$ in any of his three papers on the care of older people (Lewis, 1944, 1946; Lewis and Goldschmidt, 1943). Nor did Warren refer to Lewis or to Post's work. This is particularly surprising as Tooting Bec Hospital was also an old workhouse infirmary, overcrowded and with poor facilities, just like the hospital in which Warren began to work in 1936 (Evans, 1997; McInness, 
1990). It is of course possible that both the 1943 papers were 'in press' at the same time.

It was becoming apparent that the two disciplines - geriatrics and old age psychiatry - were emerging from different philosophical roots, despite considerable shared issues. For Lewis the inspiration was largely via the ideology of Adolph Meyer, with whom Lewis had studied in the USA. Meyer was an advocate of a holistic approach to mental illness and originated the term psychobiology to describe this method of working. He had been a profound influence on Lewis (Shepherd, 1977). The paper by Lewis and Goldschmidt (1943) and Lewis's other writing on older people (1944, 1946) was certainly Meyerian in taking a 'whole person' approach, exploring the interface between psychological, social and medical factors. Indirectly, Meyer is also likely to have influenced Post, since Henderson in Edinburgh was another former student and admirer of Meyer (Gelder, 1991).

In 1945 Lewis lectured at the Annual Meeting of the RMPA about older people's mental health needs (Lewis, 1946). Unfortunately the published version contained no reference list. Lewis again discussed the admission of older people to mental hospitals, and argued that:

the incidence of mental disorder among the elderly is considerably higher than the figure derived from mental hospital admissions alone, and that many elderly people with fairly gross mental impairment are in public assistance and similar institutions.

He gave the situation at Tooting Bec Hospital as an example. As an old workhouse infirmary rather than a mental hospital, Tooting Bec's patients were not counted in the statistics of the Board of Control for mental hospitals. The study by Affleck (1948) of people living in public assistance institutions for the chronic sick supported this observation: $37.3 \%$ of Affleck's sample living in hospitals for the chronic sick had concomitant mental illness. Thus mental illness admissions in older people were increasing, even though this was not apparent in 'first attack' mental illness statistics relating specifically to mental hospitals. He contrasted the lower admission figures in England with the increasing figures for admission to mental hospitals in New York where there were no hospitals specifically for older people, or equivalent to Tooting Bec. With a sense of alarm at the Registrar General's predictions for increasing numbers of older people in the population, he stated: 'We must regard the mental disorders of the elderly as likely to be responsible within the next 30 years for the bulk of the patients admitted to mental hospitals.' He gave some of the limitations of the figures he quoted, in particular the lack of specific diagnostic information available. Diagnosis and terminology, he said,

are in a mess ... dementia, deterioration, decay, senility and presenile psychoses are terms used without precision ... the psychologists are labouring to provide a measure of some aspects of the impairment 
common in old age, but are some way from being able to measure dementia, far less to detect it ... The clinical is probably now the most neglected field in the study of the psychiatry of ageing ... I would therefore plead for a greater interest in the straightforward clinical aspects of mental disorder as seen in the aged ... how fascinating the problems are, and how pressing the theme.

Difficulties with nosology were yet to be resolved - nearly another decade would pass before the landmark paper by Martin Roth (1955). Lewis's ideals were for the early detection of mental disorders, clinical assessment and active management. His focus was largely away from the custodial roles of mental hospitals for older people, where there was to be little change until the 1960s (Whitehead, 1970).

It is not just the content of Lewis's paper which is of interest, but also the context, as part of the scientific programme entitled 'Ageing and senility' at the Annual Meeting of the RMPA in 1945. The programme also included lectures by Helen Goldschmidt (1946), a social worker, on 'Social aspects of ageing and senility', Margaret Eysenck (1946), a psychologist, on 'The psychological aspects of ageing and senility', and Dr Derek Richter on 'Some biological changes in senility' (apparently unpublished). The ensuing discussion (RMPA, 1946) was chaired by the President of the Association, A. A. W. Petrie, whose lack of insight into needs of older people with mental illness has already been mentioned (Petrie, 1944). A number of controversial issues were raised. Dr Arthur Pool, a medical superintendent of a mental hospital (Medical Directory, 1969), looked unfavourably on a specialist service for older mentally ill people:

he would like to learn from some medical officer of Tooting Bec what it was like to be a medical officer in an institution which dealt solely with senile cases. His impression was that it was not very attractive. After all, they had to consider the medical personnel as well as the patients. (RMPA, 1946)

Despite his ambivalence, by 1952 he was consultant in charge of one of the first day hospitals in this country in Oldham, Lancashire, which had a policy of accepting patients with dementia. Ironically, in 1956 he opened a day hospital entirely for older mentally ill people in conjunction with a 32-bed psycho-geriatric in-patient unit, also in Oldham (Farndale, 1961). Interestingly, he was not the only psychiatrist to voice ambivalence. Others among the earliest appointed old age psychiatrists such as Post in 1949 (Post, 1991), and Tom Arie and Brice Pitt in the 1960s also kept a case load of younger patients, partly because the therapeutic and career rewards of working entirely with older people remained uncertain (Arie, 1991; Pitt, 1991). Time has shown them to be incorrect in their speculation, with the continuing development of the specialty of old age psychiatry into the twenty-first century. 
Another participant attending Lewis's lecture, Dr D. R. McCalman pointed out that there were already out-patient departments 'up and down the country ... beginning to play a part in this question of senility' ( $R M P A$, 1946), but with no further elaboration. Dr W. T. J. Kimber, a specialist in child psychiatry (Medical Directory, 1969), commented that there were lots of 'old folk's committees' with very definite views on the care of older people, in particular preventing older people from going into any institution at all (RMPA, 1946). Dr Iveson Russell, Medical Superintendent at Clifton Hospital, York (Medical Directory, 1969), took the empathic approach which seemed to be so lacking in much of the discussion. He is reported to have remarked that:

it seemed unlikely that they would be able to prevent themselves from growing old, and he thought the question they really ought to ask ... was as to what sort of institution they themselves would want to go into. His own choice would be for a small place, not a large one. (RMPA, 1946)

$\mathrm{He}$ also saw little advantage in larger institutions other than for research workers, but that 'the same research could be carried out by hiring a fleet of motor-cars in which research workers went out into the country and saw these people in small houses'. Four years later when Russell was president of the RMPA, unlike Petrie (1944) he at least advocated for older people, recognizing the adverse social circumstances that complicate old age and the need for small specialist residential units for the older mentally ill (Russell, 1949).

The scientific session at the 1945 Annual Meeting clearly sparked considerable discussion on the mental health of older people, from a group of senior mental health care practitioners, probably for the first time in this country. In the days prior to the development of sub-specialties of adult psychiatry, many of those present must have had a clinical awareness of mental illness in older people, and the session had the potential to make a considerable impact on contemporary psychiatric practice.

Lewis's interest in older people was to have major direct effects on the development of old age psychiatry. As Professor of Psychiatry at the Maudsley Hospital, he wanted to develop a model clinical and academic postgraduate teaching hospital with all psychiatric specialties represented. Post had worked with Lewis in the early 1940s, both at the Hammersmith Hospital and at the Mill Hill Emergency Hospital, part of the wartime Maudsley (Post, 1988), and they met again in Edinburgh at the home of Professor Henderson (Post, 1991). Lewis was aware of Post's research on older people (Lewis, 1946). These factors probably influenced the appointment of Post as assistant physician at the Maudsley Hospital in 1947 and as physician with a special responsibility for older people in 1949. By that year, Post was assessing almost all new out-patients over the age of 60 years referred to the Maudsley Hospital, and had a few designated beds on a ward at the Bethlem Royal Hospital (Norris and Post, 1954; Post, 1988). 
The setting up of a Geriatric Unit at the Bethlem Hospital (which had joined with the Maudsley at the inception of the NHS) was regarded as a 'revolutionary proposal' and created considerable opposition (Post, 1955). Both Lewis and Post had already shown a desire for a holistic, Meyerian approach to mental illness in older people. Their common approach was a good basis for future co-operation between them, especially for Post's academic and research work. His meticulous research and his reputation as an inspiring teacher was to influence further the development of mental health services for older people into future generations.

Other advances in the 1940s also had an effect on the development of accurate diagnosis and service provision for the elderly mentally ill. For example, there was progress in understanding the psychology of ageing and how to measure intellectual impairment. Halstead and Margaret Eysenck were among the psychologists beginning to quantify cognitive changes in dementia. Both investigated subjects at Tooting Bec Hospital, and both acknowledged in their research the support received from Aubrey Lewis and the Medical Superintendent of Tooting Bec, Dr Turnbull (Eysenck, 1945; Halstead, 1944). Eysenck had also delivered a paper at the RMPA Annual Meeting in 1945. Some recent observations were pointing to a change in attitude to older people: 'a surprising and interesting fact, showing that the older person retains a desire to learn'. But perhaps more importantly, Eysenck acknowledged the state of ignorance about older people's psychology and proposed large-scale longitudinal studies to look at intellectual, emotional and other changes over the life span. To set this all in context, however, the development of instruments for quantifying psychological function was still in its infancy. For example both J. C. Raven and D. Wechsler, contemporaries of Eysenck, were in the process of developing their widely accepted psychological assessment rating scales. However, there were still no specific tools validated for the assessment of older people as an aid to accurate diagnosis.

Recently introduced electroconvulsive therapy (ECT) was also leading to a change in philosophy towards the treatment of older people's mental illness. Mayer-Gross (1945), among others (Gallinek 1948; Kino and Thorpe, 1946), noted that the results of ECT in older people were 'at least equal those in younger age groups considering the much poorer outlook of these psychoses in higher age'. The success of ECT in some forms of mental illness in older people and its failure in others was striking. This observation was one of the reasons for new efforts to understand aetiological factors involved in older people's mental illness, and to find a satisfactory basis for classification and accurate diagnosis, ultimately leading to changes in the clinical management of mental illness in older people.

\section{Mental health in the community}

Stengel (1943) had commented that most patients with dementias came to 
psychiatric care at a late stage in their illness, and therefore the mental hospital population did not reflect the true incidence of these illnesses. In addition, he thought it likely that many sufferers died from intercurrent illnesses before reaching a stage of dementia which required mental hospital admission. Epidemiological studies of mental illness in old age were necessary to begin to elucidate the patterns of incidence and prevalence in the community.

Community surveys were being undertaken in the mid-1940s. The first was by the Rowntree Committee of the Nuffield Foundation (Rowntree, 1947) and the second by Sheldon (1948). The Nuffield Foundation study was largely to acquire information about the domestic backgrounds of older people living in typical urban and rural areas of England and Wales. Sheldon then went on to follow up those in the Wolverhampton part of the study to identify health needs further. Sheldon was director of medicine at the Royal Hospital in Wolverhampton and carried out the study in his spare time. He was made a Freeman of Wolverhampton, and memorials there still commemorate his work (personal communication, Professor D. J. Jolley, 2004). His random sample of 477 people - women over the age of 60 and men over 65 - was derived from the register of ration cards; data were collected from May 1945 until January 1947. Not only had Aubrey Lewis been a member of the Rowntree Committee (Post, 1988), but the questionnaire designed to assess mental health in Sheldon's study had also been devised by him (Sheldon, 1948). However, in the context of a survey, despite his interest and expertise in mental health, Lewis's questionnaire appeared far from adequate:

while most people are quite prepared to discuss their intellectual state over such questions as memory and activity, few will accept questions relating to habits ... there would be no guarantee of an accurate answer, since, apart from other considerations, the subject would often be quite unconscious of the fact.

Sheldon went on to suggest that future surveys should be done by a psychiatrist, and with a collateral history from relatives. Another limitation of the survey was that the results were symptom- rather than diagnosis-based. However, in terms of the burden of mental illness, his conclusions were that $82 \%$ of his sample were fully normal, $11 \%$ had 'faculties slightly impaired', $4 \%$ were demented, forgetful or childish and difficult to live with, and a small remainder were 'eccentric in habits' but otherwise mentally well. Subjectively Sheldon's view of the people investigated was:

one of admiration for the mental vigour and 'guts' of the old people; and one cannot avoid the suggestion that the facts of living in the environment they are used to, of having something to do, and of being still able to feel necessary to the world are important factors in producing this state of affairs, and may help to explain why the mental level of old people living in their homes appears to be so much better than that of those living in institutions. 
As a psychiatrist specifically working with older people, Post's comment (1949) on Sheldon's study was that 'It is reassuring to have confirmation, scientifically obtained, of the impression gained in everyday contact with old people, that the overwhelming majority retain their mental faculties to the full.' From the view of mental health professionals working with older adults in psychiatric hospitals, this was not always apparent. Illness in older people is an exception, not the norm.

\section{The National Health Service (NHS) and other bodies influencing provision of care in the late 1940s}

Before 1946 there was little expectation that mental health and learning disability services would be included in the new health service, and therefore little planning. The 1946 National Health Service Bill, however, clearly included the provision of all forms of special hospitals, including mental hospital in-patient and out-patient services (BMF, 1946). The established Board of Control for mental hospitals was taken by surprise, and there was considerable conflict between it and the new NHS administration. In the London area in particular, many hospitals had suffered bomb damage and were in a poor state of repair. Even when requisitioned property was returned, the hospital authorities often lacked the finance or nursing staff to be able to restore services. There was enormous overcrowding. The NHS therefore inherited an unsuitable and partly derelict hospital stock, a management structure ill-prepared for change, and increasing pressures to provide services. Among these pressures was the rising population of older people and increasing numbers of older people requiring mental health care (BMA, 1947; Webster, 1991).

When the National Health Service (NHS) came into being in 1948, a dozen standing advisory committees were set up relating to various aspects of health care. Many of these committees had little influence on the strategic development of the health service. However, the Mental Health Standing Advisory Committee (SAC $(\mathrm{MH})$ ) was a powerful force making a determined effort to influence events (Webster, 1991).

Lewis retained his interest in older people and at the end of the 1940s was active in the new SAC $(\mathrm{MH})$. He was not always popular because of his aggressive and acerbic style, but he was certainly aware of the pressing clinical issues. At the first meeting of the SAC $(\mathrm{MH})$ in March 1949, the increasing demand for care for elderly patients was noted. The first initiative under the NHS concerning health needs of older people was to ask the SAC $(\mathrm{MH})$ to provide advice on mental illness in elderly people (Webster, 1991).

By the end of the decade there had been two important documents relating to the care of older people, The Care and Treatment of the Elderly and Infirm published by the British Medical Association (BMA) in 1947, and the $\mathrm{SAC}(\mathrm{MH})$ report Care of the Aged in 1949. 
The 1947 BMA report emphasized that with improved treatment of previously fatal acute illnesses, such as antibiotics for infections, there would be more serious chronic illness, including mental illness. The BMA advocated a rehabilitation regime and less reliance on institutional accommodation. Long-stay facilities had to be available, however, for those who were unable to return to independent living, so as not to block beds. Services were to be for people over 60 years old (in contrast to the $\mathrm{SAC}(\mathrm{MH})$ recommendation of 65 years). Geriatric units should be established. Short-stay units were to be for thorough medical assessment and treatment, and they should have small wards including single-room accommodation. Within these geriatric units there should be adequate facilities with advice from a visiting psychiatrist for managing psychiatric disorders. It was proposed that longstay annexes should be part of geriatric departments, but these annexes should always be local to the patients' friends and relatives. Admission to the long-stay annexes was to be only via the geriatric assessment ward, so that it was absolutely certain that no remediable pathology had been overlooked. However, this sole route into care was hotly debated; for example, the $\mathrm{SAC}(\mathrm{MH})$ advocated a variety of routes to long-stay accommodation, including from home or from mental hospitals (Cook, Dax and Maclay, 1952).

The BMA committee had included a large number of influential geriatricians. Several members of the newly founded Medical Society for the Care of the Elderly (MSCE) in 1947, later the British Geriatrics Society (BGS) - Lord Amulree, Eric Brooke, Lionel Cosin and Marjory Warren - were also on the BMA committee (Barton and Mulley, 2003; BMA, 1947). Lord Amulree was both a consultant geriatrician, and a member of the Ministry of Health, while Eric Brooke was physician superintendent at St Helier's Hospital, Carshalton, and later consultant geriatrician in Southampton (Barton and Mulley, 2003). Lionel Cosin, was a pioneer of the day hospital for elderly patients at Cowley Road Hospital, Oxford. His research on the management of dementia, in collaboration with psychiatrists, occupational therapists and psychologists, put into practice his ideals of multidisciplinary working in the 1950s (Cosin, Mort, Post, Westropp and Williams, 1957, 1958). However, he had a poor view of psychogeriatricians, stating that they were 'hallucinating with their hallucinating patients' and the 'function of the psychiatrist is to depart from clinical responsibility' (Cosin, 1991). The only identifiable psychiatrist on the list of members of the BMA committee was Eric Guttmann. Although a well-known neuropsychiatrist and respected clinician at the Maudsley Hospital, he did not specifically have a role working with older people. $\mathrm{He}$ was a colleague of Aubrey Lewis, and one just wonders if his position on this committee was delegated to him by Lewis. The influence of the geriatricians would have been to bring psychiatric care into their units where they saw the bulk of their work. It is therefore hardly surprising that the BMA committee's outcome was one of proposing a geriatric-led service, with a subordinate role for psychiatry. 
The SAC $(\mathrm{MH})$, with more psychiatric input and Aubrey Lewis's influence, proposed the establishment of geriatric departments containing specific psychiatric observation sections, attached to general and teaching hospitals. It also proposed the development of long-stay annexes attached to geriatric departments or mental hospitals. However, the overall final outcome from both committees, summarized in the report 'Care of the aged suffering from mental infirmity' (Ministry of Health, 1950), was for short-term psychogeriatric assessment units within geriatric departments, geriatric-led with psychiatry involvement. There were also to be long-stay annexes in geographical proximity to acute and mental hospitals and the patients' homes (Ministry of Health, 1950). However, even before this, Lewis was already planning his psychiatric unit for older people within the Bethlem Hospital which only admitted voluntary patients with illnesses thought to be treatable. Thus, two strands of mental health facilities for older people were becoming established, one with geriatrics as the primary service with psychiatrists having some role, the other with psychiatrists taking the lead in managing and treating mental illness in older people.

This dichotomy in ideal working practices lasted for many years, and may have undermined progress. Twenty years later, 'Care of the aged suffering from mental infirmity' was quoted in the Department of Health and Social Security circular Psycho-geriatric Assessment Units (DHSS, 1970). This still advocated for the psycho-geriatric unit within geriatric departments. However, Services for Mental Illness Related to Old Age (DHSS, 1972), formulated by psychiatrists working with older people, took a broader approach, with psychogeriatrics as a more community, psychiatrically led service standing independent from geriatrics. The model of the psycho-geriatric unit within geriatric units never really became established. Ultimately, the latter approach of psychiatrists leading their own service, based on the model of Aubrey Lewis, became widely adopted.

Despite the ultimate shared goal of improving the well-being of older people, old age psychiatry and geriatrics developed separately from their different philosophies in the 1940s. Service models proposed were also different. Over many years the differences rather than common ground predominated. For a variety of reasons there were few links between psychiatrists for older people and geriatricians. Firstly, there were very few psychiatrists working with older people and, in addition, the two disciplines remained geographically distant, most geriatricians and psychiatrists working in different sorts of hospitals. The negative views towards psychogeriatricians expressed by Cosin (1991) may have also undermined service development. George Adams (1991), another pioneering geriatrician, stated that 'psychogeriatricians are not proper doctors'. Although there was intermittent joint clinical working between them in the 1950s and 1960s (Donovan, Williams and Wilson, 1971; Fish and Williamson, 1964; Morton, Barker and Macmillan, 1968), more formal links did not develop until the 1970s with 
the instigation of a Working Party between the BGS and the Royal College of Psychiatrists. This had been set up with the remit of 'establishing an agreed policy on the on the development of the psychogeriatric services to meet the growing needs'. By that time the BGS was an established body, but old age psychiatrists were still a fledgling group (Royal College of Psychiatrists, 1972). The deliberations and developments of the 1940s may in part at least have been responsible for the slow pace of change over subsequent decades. It is debatable how much was also due to Aubrey Lewis's strong will in selectively setting up an acute old age psychiatric unit at the Bethlem Hospital, and ignoring other aspects of the Ministry of Health circular such as long-stay facilities.

Another factor which may have been responsible for the slow change may have been the honest but unfortunate statement by the Ministry of Health (1950) that 'present conditions of financial stringency limit opportunities for action at this time'. Cook et al. (1952) also pointed out the lack of implementation of the BMA and SAC $(\mathrm{MH})$ reports, because of financial costs of building and staffing. This had been anticipated by the BMA committee (1947):

Owing to the present restrictions on building construction and shortages of trained staff, progress in achieving an improved medical service for the elderly ill will inevitably be slow. Many years must pass before any scheme ... can be brought fully into operation throughout the country.

But the BMA report concluded by quoting a committee member pleading for a change in attitude: 'what is needed more than anything material is an awakening of the whole community to the existence in their midst of a state of affairs often tragic in its melancholy and suffering.'

Then, as over subsequent decades, it appeared hard for any government actually to prioritize and fund a model service for older people with mental illness, despite moral and humane obligations and the philosophy of the Welfare State.

\section{The role of refugee health care workers}

A disproportionately large number of the people involved with the developments for older people with mental illness, and mentioned in this paper, were recent immigrants to England, some of whom had fled Nazi persecution. Felix Post, Erwin Stengel and Eric Guttmann had all come to England to escape the Nazi regime and had all experienced internment in the Isle of Man as enemy aliens (Jenner, 1991; Post, 1988). Helen Goldschmidt, Eric Guttmann and Willi Mayer-Gross had all been brought to Britain on Rockefeller Foundation fellowships (Lewis and Goldschmidt, 1943; Slater, 1981/1993), Guttmann and Mayer-Gross at the instigation of Professor Edward Mapother, medical superintendent of the Maudsley Hospital. From 
1933 the Rockefeller Foundation had invested considerably in relocating hundreds of persecuted doctors, scientists and scholars from Nazi Germany, and later Austria, to other locations (Angel, Jones and Neve, 2003). Lionel Cosin was born in Britain to immigrant Jewish parents, and had been awarded his Doctorate of Medicine from Vienna University (Cooper 2003; Medical Directory, 1969). Aubrey Lewis was also Jewish. His parents had emigrated from Eastern Europe, via London to Australia. It is alleged that Lewis may also have experienced discrimination in his career. Shepherd (1977) states that, 'it was made clear that opportunities would not be made available' for him to pursue his career in psychiatry in Australia, so he came to England.

All these workers aimed to promote the care and well-being of the elderly mentally ill, working with some of the most disadvantaged people in society. It is hard to disregard the personal histories of these individuals in their choice of career. It may well be that job opportunities were more limited for them due to their status as immigrants, or anti-German feelings after World War II or anti-Semitism (Cooper 2003; Rollin and Merry 2004). The unpopularity of work with older mentally ill people was reflected in Dr Arthur Pool's comments at the RMPA meeting in 1945 (RMPA, 1946), and psychiatry and geriatrics were less prestigious and popular medical specialties than medicine or surgery, for example. The less prestigious specialties may have offered more financial and employment security. In addition, it may well be that experiences of discrimination, and the fear of or actual experience of incarceration, influenced these immigrant workers to take an active role in developing appropriate treatment services for older mentally ill people.

\section{The 1940s and into the future}

Attitudes to older people with mental illness and knowledge about the illnesses they suffered were beginning to change in the 1940s. From a position of assuming that all mental illness among older people was inevitable and irreversible, management based on accurate diagnosis and the knowledge of potential outcome was beginning to emerge. It was well into the 1950s when this became more widely known, mainly after the study by Roth (1955). Community surveys were beginning to identify mentally ill older people coping outside mental hospitals (Sheldon, 1948). Efforts were being made clinically, by Lewis and Post, to admit, assess and treat older people and keep them out of mental hospitals (Post, 1955). However, over the country as a whole, progress was slow, with only a handful of joint clinical projects between psychiatrists and geriatricians and a few day hospitals (Farndale, 1961). There was really little widespread change until the 1960s (Whitehead, 1970).

In the 1940s, treatment of depression with ECT indicated that older people could get better after an episode of illness (Mayer-Gross, 1945). Psychological tools were becoming available to make reliable neuropsychological assessments 
(Eysenck, 1946). Post (1949) - as Lewis had also done (Lewis and Goldschmidt, 1943) - emphasized the roles of psychology and social work as vital to making progress in the field of psychiatry for older people.

In 1949 Post conveniently reviewed recent progress. His primary concern, like that of other authors (BMA, 1947; Lewis, 1946; Lewis and Goldschmidt, 1943; Sheldon, 1948), remained the increasing population of older people, and how existing services could deal with their psychiatric disorders. His review also raised issues of aetiology, exploring the possibilities of what could be done to prevent mental illness in older people, and, still before the development of any specific anti-psychotic and anti-depressant medications, what could be done to treat it.

At the end of the 1940s, many important questions remained unanswered such as the differential diagnoses and classification of mental illnesses in older people and treatment and prognosis of different conditions. Some of these were taken up in the 1950s with the establishment of the Geriatrics sub-committee of the Research and Clinical section of the RMPA (RMPA, 1951-58). This included various doctors such as Affleck, Post and Richter who were already expressing an interest in older adults' mental health from the 1940s; others who made important contributions were Roth (Roth, 1955; Roth and Morrissy, 1952, and other work), Cook et al. (1952) and Macmillan (1960, 1967; Macmillan and Shaw, 1966). The need to implement recommendations based on the $\mathrm{BMA}$ and $\mathrm{SAC}(\mathrm{MH})$ reports was to be explored and expanded further over the next decade and beyond, but taken up in the short-term by the Ministry of Health in 1950 (Ministry of Health, 1950). Apart from a few clinical initiatives, links with geriatricians remained weak until the 1970s.

Although Lewis's resolve to create an older people's assessment unit at the Bethlem may in some ways have had a negative effect on developing more comprehensive services, his foresight, interest in the subject and his leadership within the field of psychiatry were undoubtedly significant contributory factors in the development of care and treatment for older mentally ill people. At the Bethlem, Post became renowned for his passionate interest in older people and superb clinical teaching. His wards became a focus of inspiration and learning for future clinicians including numerous professors of old age psychiatry, such as Tom Arie, Raymond Levy, Robin Jacoby, Ken Shulman and David Jolley.

In summary, if one were to date the origins of the specialty of old age psychiatry - the philosophy of a multidisciplinary approach to assessment and treatment of mental illness in older people - it must be to the middle of the 1940s. The publication of Lewis and Goldschmidt's work in 1943, Post's paper in 1944, and the RMPA scientific meeting on 'Ageing and senility' in 1945 (publ. 1946) identify the beginnings of change in the philosophy of care for older people with mental illness which set the scene for research, teaching and service developments into the future. 


\section{Acknowledgements}

I am very grateful to the librarians in the John Squire Medical Library at Northwick Park Hospital for their assistance with retrieving books from the stacks and obtaining inter-library loans. This work was carried out with the support of a Wellcome Trust Leave Award in the History of Medicine.

\section{References}

Adams, G. (1991) Interviewed by Anthea Holmes. In Oral History of Geriatrics as a Medical Specialty. Retrieved from http://cadensa.bl.uk/uhtbin/cgisirsi/sQDTDSuI2F/204950006/9.

Affleck, J. W. (1948) Psychiatric disorders among the chronic sick in Hospital. Fournal of Mental Science, 94, 33-45.

Angel, K., Jones, E. and Neve, M. (eds) (2003) European Psychiatry on the Eve of War: Aubrey Lewis, the Maudsley Hospital and the Rockefeller Foundation in the 1930s (London: Wellcome Trust Centre for the History of Medicine at UCL).

Anon. (1935a) Personality and age. Lancet, (2), 672.

Anon. (1935b) Some common mental disorders. Lancet, (1), 327.

Anon. (1935c) Book review Care of the Aged, the Dying and the Dead by Worcester A. Lancet, (2), 430.

Anon. (1937a) Surgery in old age. Lancet, (1), 1182.

Anon. (1937b) Poor old things. Lancet, (2), 1175-6.

Anon. (1938) Old age in mind and body. Lancet, (2), 87-8.

Anon. (1939) Surgery in old age. Lancet, (1), 1210-1.

Anon. (1973) E. Stengel [obituary]. British Medical fournal, (2), 668.

Arie, T. (1991) Interviewed by Hazel Houghton. In Oral History of Geriatrics as a Medical Specialty. Retrieved from http://cadensa.bl.uk/uhtbin/cgisirsi/sQDTDSuI2F/204950006/9.

Barton, A. and Mulley, G. (2003) History of the development of geriatric medicine in the UK. Postgraduate Medical fournal, 79, 229-34.

Berkenau, P. (1940) Vitamin C in senile psychosis (a preliminary report). Fournal of Mental Science, 86, 675-9.

BMA (1947) The Care and Treatment of the Elderly and Infirm (London: British Medical Association).

BMf (1946) National Health Service Bill HMSO Cmd 6761: summary of the proposed new service. British Medical fournal, (1), 461-74.

Brody, M. B. (1942a) The measurement of dementia. Fournal of Mental Science, 88, 317-27.

Brody, M. B. (1942b) A psychometric study of dementia. Fournal of Mental Science, 88, 504-25.

Cook, L. C., Dax, E. Cunningham and Maclay, W. S. (1952) The geriatric problem in mental hospitals. Lancet, (1), 377-82.

Cooper, J. (2003) Pride versus Prejudice. Fewish Doctors and Lawyers in England 1890-1990 (Oxford: The Littman Library of Jewish Civilisation).

Cosin, L. (1991) Interviewed by Professor Margot Jefferys. In Oral History of Geriatrics as a Medical Specialty. Retrieved from http://cadensa.bl.uk/uhtbin/cgisirsi/FJzkUQpLyI/ $204950006 / 9$.

Cosin, L. Z., Mort, M., Post, F., Westropp, C. and Williams, M. (1957) Persistent senile confusion: a study of 50 consecutive cases. International fournal of Social Psychiatry, 3, $195-202$.

Cosin, L. Z., Mort, M., Post, F., Westropp, C. and Williams, M. (1958) Experimental treatment of persistent senile confusion. International fournal of Social Psychiatry, 4, $24-42$. 
Cowdry, E. V. (1942) Problems of Ageing: Biological and Medical Aspects, 2nd edn (Baltimore, MD: Williams and Wilkins Co.).

DHSS (1970) Psycho-geriatric Assessment Units (London: HMSO, HM (70) 11).

DHSS (1972) Services for Mental Illness Related to Old Age (London: HMSO, HM (72) 71).

Donovan, J. F., Williams, I. E. I. and Wilson, T. S. (1971) A fully integrated psychogeriatric service. In D. W. K. Kay and A. Walk (eds), Recent Developments in Psychogeriatrics: $A$ Symposium (London: RMPA), 113-25.

Evans, J. G. (1997) Geriatric medicine: a brief history. British Medical fournal, 315, 1075-7.

Eysenck, M. D. (1945) A study of certain qualitative aspects of problem solving behaviour in senile dementia patients. Fournal of Mental Science, 91, 337-45.

Eysenck, M. D. (1946) The psychological aspects of ageing and senility. Fournal of Mental Science, 92, 171-81.

Farndale, J. (1961) The Day Hospital Movement in Great Britain (Oxford: Pergamon Press).

Fish, F. and Williamson, J. (1964) A delirium unit in an acute geriatric hospital. Gerontology Clinics, 6, 71-80.

Gallinek, A. (1948) The nature of affective and paranoid disorders during the senium in the light of electroconvulsive therapy. Fournal of Nervous and Mental Disorders, 108, 293-303.

Gelder, M. (1991) Adolph Meyer and his influence on British psychiatry. In G. E. Berrios and H. Freeman (eds), 150 Years of British psychiatry 1841-1991 (London: Gaskell), 419-35.

Goldschmidt, H. (1946) Social aspects of ageing and senility. Fournal of Mental Science, 92, 182-94.

Halstead, H. (1944) Mental tests in senile dementia. Fournal of Mental Science, 90, 720-7.

Jenner, F. A. (1991) Erwin Stengel. A personal memoir. In G. E. Berrios and H. Freeman (eds), 150 Years of British Psychiatry 1841-1991 (London: Gaskell), 436-44.

Kino, F. F. and Thorpe, F. T. (1946) Electrical convulsion therapy in 500 selected psychotics. Fournal of Mental Science, 92, 138-45.

Lawton, G. (1940) Old age and ageing. The present state of scientific knowledge. Section meeting 1939. American fournal of Orthopsychiatry, 10, 27-87.

Lawton, G. (1944) Chairman of round table discussion: psychological problems of later maturity. American fournal of Orthopsychiatry, 14, 266-84.

Lewis, A. (attrib.) (1944) The problem of ageing [leading article]. Lancet, (2), 569.

Lewis, A. (1946) Ageing and senility: a major problem of psychiatry. Fournal of Mental Science, 92, 150-70.

Lewis, A. (2003) Introduction to report. In Angel, Jones and Neve (see above).

Lewis, A. and Goldschmidt, H. (1943) Social causes for admission to a mental hospital for the aged. Sociological Review, 35, 86-98.

Macmillan, D. (1960) Preventative geriatrics. Lancet, (2), 1439-41.

Macmillan, D. (1967) Problems of a geriatric mental health service. British fournal of Psychiatry, 113, 175-81.

Macmillan, D. and Shaw, P (1966) Senile breakdown in standards of personal and environmental cleanliness. British Medical fournal, (2), 1032-7.

Mayer-Gross, W. (1944) Arteriosclerotic, senile and presenile psychoses. Fournal of Mental Science, 90, 316-27.

Mayer-Gross, W. (1945) Electric convulsion treatment in patients over 60. Fournal of Mental Science, $91,101-3$.

McInness, E. M. (1990) St Thomas' Hospital, 2nd edn (London: Special Trustees for St Thomas' Hospital).

Medical Directory (1969) Medical Directory 125th Annual Issue (London: Churchill).

Ministry of Health (1950) Care of the aged suffering from mental infirmity. Unpublished report HMC (50) 25; copy in archives of King's Fund, London. 
Morton, E. V. B., Barker, M. E. and Macmillan, D. (1968) The joint assessment and early treatment unit in geriatrics. Gerontology Clinics, 10, 65-73.

Newton, R. D. (1948) The identity of Alzheimer's disease and senile dementia and their relationship to senility. Fournal of Mental Science, 94, 225-49.

Norris, V. and Post, F. (1954) Treatment of psychiatric patients: use of a diagnostic classification. British Medical fournal, (1), 675-9.

Peters, I. L. (1944) Rehabilitation applied to older persons. American fournal of Orthopsychiatry, $14,279-82$.

Petrie, A. A. W. (1944) Mental health services - present and future. Fournal of Mental Science, 90, 3-19.

Pitt, B. (1991) Interviewed by Professor Margot Jefferys. In Oral History of Geriatrics as a Medical Specialty. Retrieved from http://cadensa.bl.uk/uhtbin/cgisirsi/fGG2QEWPDu/204950006/9.

Post, F. (1944) Some problems arising from a study of mental patients over the age of 60 years. Fournal of Mental Science, 90, 554-65.

Post, F. (1949) Mental aspects of senescence. British Medical Bulletin, 6(1-2), 54-7.

Post, F. (1951) The outcome of mental breakdown in old age. British Medical fournal, (1), 436-8.

Post, F. (1955) Geriatric unit. Bethlem-Maudsley Gazette, 1, 270-1.

Post, F. (1962) The Significance of Affective Symptoms in Old Age: A Follow Up Study of 100 Patients (London: Oxford University Press; Maudsley Monograph No. 10).

Post, F. (1988). Felix Post talking to Brian Barraclough. In Greg Wilkinson (ed.), Talking about Psychiatry (London: Gaskell).

Post, F. (1991) Interviewed by Professor Margot Jefferys. In Oral History of Geriatrics as a Medical Specialty. Retrieved from http://cadensa.bl.uk/uhtbin/cgisirsi/e3QjitAeQX/204950006/9.

Remp, D. G., Rosen, S. R., Ziegler, J. B. and Cameron, D. E. (1940) Ascorbic acid levels in patients suffering from psychoses of the senium. Fournal of Mental Science, 86, 534-7.

RMPA (1946) [Discussion at Royal Medico Psychological Association Annual Meeting, 1945]. Fournal of Mental Science, 92, 191-4.

RMPA (1951-58) Geriatrics sub-committee of the Research and Clinical section of the RMPA, Minutes 1951-1958; held in the archives of the Royal College of Psychiatrists.

Rogers, A. and Pilgrim, D. (1996) Mental Health Policy in Britain. A Critical Introduction (London: Macmillan Press).

Rollin, H. and Merry, P. (2004) Obituary: Julius Merry. Psychiatric Bulletin, 28, 107-8.

Roth, M. (1955) The natural history of mental disorders in old age. Fournal of Mental Science, 101, 281-301.

Roth, M. and Morrissey, J. O. (1952) Problems in the diagnosis and classification of mental disorder in old age: with a study of case material. Fournal of Mental Science, 98, 66-80.

Rowntree, B. S. (1947) Old People (London: OUP).

Royal College of Psychiatrists (1972). Council meeting minutes, 15/72 9.2.72; held in the College's archives.

Royal Medico Psychological Association, see RMPA above.

Russell, J. I. (1949) The role of the mental hospital in the National Health Service. Fournal of Mental Science, 95, 51-60.

Schilder, P. (1940) Psychiatric aspects of old age and ageing. American fournal of Orthopsychiatry, $10,62-9$.

Sheldon, J. H. (1948) The Social Medicine of Old Age (London: Oxford University Press).

Shepherd, M. (1977) The making of a psychiatrist. British fournal of Psychiatry, 131, 238-42.

Shepherd, M. (1986) A representative psychiatrist: the career, contributions and legacies of Sir Aubrey Lewis. Psychological Medicine Monograph, Supplement 10, 5-31. 
Slater, E. (1981) Eliot Slater talking to Brian Barraclough. In Greg Wilkinson (ed.) (1993) Talking about Psychiatry (London: Gaskell).

SAC $(\mathrm{MH})$, Standing Advisory Committee on Mental Health (1949). Care of the Aged, $\mathrm{SAC}(\mathrm{MH})$ (49) 14; quoted by Cook et al. (1952), and others.

Stengel, E. (1943) A study on the symptomatology and differential diagnosis of Alzheimer's disease and Pick's disease. Fournal of Mental Science, 89, 1-20.

Stengel, E. (1965) The causation and prevention of suicide in old age. In World Psychiatric Association Symposium (Manchester: Geigy), 52-7.

Wardle, C. J. (1989) Mental health services for children and adolescents. South West Psychiatry, 2, 7-17.

Warren, M. (1943) Care of chronic sick. British Medical fournal, (2), 822-3.

Warren, M. (1946) Care of the chronic aged sick. Lancet, (2), 841-3.

Webster, C. (1991) Psychiatry and the early National Health Service: the role of the Mental Health Standing Advisory Committee. In G. E. Berrios and H. Freeman (eds), 150 Years of British Psychiatry 1841-1991 (London: Gaskell), 103-16.

Whitehead, A. (1970) In the Service of Old Age (Harmondsworth, UK: Pelican Books Ltd). 